\title{
X-linked mandibulofacial dysostosis
}

INSERM

\section{Source}

INSERM. (1999). Orphanet: an online rare disease and orphan drug data base. $\underline{X \text {-linked }}$ mandibulofacial dysostosis. ORPHA:1131

X-linked mandibulofacial dysostosis is an extremely rare multiple congenital abnormality syndrome that is characterized by microcephaly, malar hypoplasia with downslanting palpebral fissures, highly arched palate, apparently low-set and protruding ears, micrognathia, short stature, bilateral hearing loss, and learning disability. Occasionally, additional features have been observed such as bilateral cryptorchidism, cardiac valvular lesions, body asymmetry, and pectus excavatum. 